\title{
Alkali Cation Effect on CO2 Electroreduction to CO: A Local Colligative Property
}

\section{Seung-Jae Shin}

Korea Advanced Institute of Science and Technology https://orcid.org/0000-0002-5530-4453

\section{Hansol Choi}

Gwangju Institute of Science and Technology https://orcid.org/0000-0001-7318-8815

\section{Stefan Ringe}

Daegu Gyeongbuk Institute of Science and Technology https://orcid.org/0000-0002-7804-1406

\section{Da Hye Won}

Korea Institute of Science and Technology https://orcid.org/0000-0002-7589-7866

\section{Chang Hyuck Choi}

Gwangju Institute of Science and Technology https://orcid.org/0000-0002-2231-6116

Hyungjun Kim ( $\square$ linus16@kaist.ac.kr)

Korea Advanced Institute of Science and Technology https://orcid.org/0000-0001-8261-9381

\section{Article}

Keywords:

Posted Date: December 16th, 2021

DOI: https://doi.org/10.21203/rs.3.rs-1157577/v1

License: (c) (i) This work is licensed under a Creative Commons Attribution 4.0 International License. Read Full License

Version of Record: A version of this preprint was published at Nature Communications on September 19th, 2022. See the published version at https://doi.org/10.1038/s41467-022-33199-8. 


\title{
Alkali Cation Effect on $\mathrm{CO}_{2}$ Electroreduction to CO: A Local Colligative Property
}

\author{
AUTHORS: Seung-Jae Shin,,${ }^{1, \dagger}$ Hansol Choi, ${ }^{2, \dagger}$ Stefan Ringe, ${ }^{3}$ Da Hye Won, ${ }^{4}$ Chang Hyuck Choi, ${ }^{2, *}$ \\ and Hyungjun $\mathrm{Kim}^{1, *}$
}

\section{Affiliations:}

${ }^{1}$ Department of Chemistry, Korea Advanced Institute of Science and Technology, Daejeon 34141, Republic of Korea.

${ }^{2}$ School of Materials Science and Engineering, Gwangju Institute of Science and Technology, Gwangju 61005, Republic of Korea.

${ }^{3}$ Department of Energy Science and Engineering, Daegu Gyeongbuk Institute of Science and Technology, Daegu 42988, Republic of Korea.

${ }^{4}$ Clean Energy Research Center, Korea Institute of Science and Technology, Seoul 02792, Republic of Korea.

*Corresponding authors: chchoi@gist.ac.kr (C.H.C) and linus16@kaist.ac.kr (H.K.)

$15 \dagger$ These authors contributed equally to this work.
ABSTRACT: Converting carbon dioxide $\left(\mathrm{CO}_{2}\right)$ into valuable products is one of the most important processes for a sustainable society. Especially, the electrochemical $\mathrm{CO}_{2}$ reduction reaction $\left(\mathrm{CO}_{2} \mathrm{RR}\right)$ offers an effective means, but its reaction mechanism is not yet fully understood. Here, we demonstrate that cation-coupled electron transfer (CCET) is a rate-determining step in the $\mathrm{CO}_{2} \mathrm{RR}$ to carbon monoxide. The first-principles-based multiscale simulation identifies a single cation that coordinates a $\mathrm{CO}_{2}{ }^{-}$intermediate adsorbed on $\mathrm{Ag}$ electrode. The CCET is experimentally verified by a collapse of the $\mathrm{CO}_{2} \mathrm{RR}$ polarization curves upon correcting Nernstianly for a bulk cation concentration. As further 
confirmation, a kinetic study shows that the $\mathrm{CO}_{2} \mathrm{RR}$ obeys first-order kinetics on a local cation concentration. Finally, this work unveils that the cation effect on $\mathrm{CO}_{2} \mathrm{RR}$ originates from the local colligative property, and further highlights the importance of ion-pairing tendency for electrochemical interface design to achieve high-performance $\mathrm{CO}_{2}$ electrolysis. 


\section{INTRODUCTION}

As a carbon dioxide $\left(\mathrm{CO}_{2}\right)$ mitigation technology, electrochemical $\mathrm{CO}_{2}$ reduction reaction $\left(\mathrm{CO}_{2} \mathrm{RR}\right)$ is considered promising for converting $\mathrm{CO}_{2}$ into valuable chemicals and fuels. ${ }^{1-3}$ Among the possible products that can be formed via a multi-electron reduction of $\mathrm{CO}_{2}$, two-electron-reduced carbon monoxide $(\mathrm{CO})$ is of prime interest due to not only its practical importance as a constituent of a syngas, ${ }^{4}$ but also its mechanistic importance as a key intermediate for $\mathrm{C}-\mathrm{C}$ bond coupling. ${ }^{5-7}$ Despite the simplicity of the $\mathrm{CO}_{2} \mathrm{RR}$ to $\mathrm{CO}$, which can be selectively catalyzed on $\mathrm{Au}$ or Ag surfaces, ${ }^{8,9}$ a full understanding of its mechanism is still not yet at hand, particularly regarding the details of the ratedetermining first reduction step..$^{10-14}$

10 The most intriguing and widely discussed phenomenon is the activity dependency of the $\mathrm{CO}_{2} \mathrm{RR}$ on species of alkali metal cation in the electrolyte, often termed a "cation effect". ${ }^{15}$ In 2016, Singh et al. demonstrated that the $\mathrm{CO}_{2} \mathrm{RR}$ on the Ag surface shows an activity trend of $\mathrm{Cs}^{+}>\mathrm{Rb}^{+}>\mathrm{K}^{+}>\mathrm{Na}^{+}>$ $\mathrm{Li}^{+}{ }^{16}$ Since the first reduction step was thought to occur through proton-coupled electron transfer (PCET), ${ }^{17-20}$ they ascribed this trend to the different $\mathrm{pKa}$ values of alkali metal cations, which could alter the local $\mathrm{pH}$ at the electrochemical interface. However, little after, various other studies have indicated the possibility for a rate-determining step (RDS) involving no proton transfer. ${ }^{21,22}$ For example, Ringe et al. found a partial current density of $\mathrm{CO}\left(j_{\mathrm{CO}}\right)$ to be independent of the $\mathrm{pH}$ even under acidic conditions. ${ }^{13}$ Consequently, they proposed another mechanism for the cation effect, called a "field effect", ${ }^{23}$ by applying an ion-size-dependent continuum surface charging model. Although the $\mathrm{CO}_{2}$ molecule remains in a linear form without binding to uncharged $\mathrm{Ag}$ or Au surface based on density functional theory (DFT) calculations, the adsorption of $\mathrm{CO}_{2}$ was found to be accompanied by a bending of the molecule driven by the non-zero net charge of the surface and the corresponding electric double layer (EDL) field under the $\mathrm{CO}_{2} \mathrm{RR}$ conditions. ${ }^{13,23}$ Furthermore, the long-range electrostatic interaction between the electric field and an adsorbate dipole was attributed to stabilizing the $\mathrm{CO}_{2}$ adsorbate more for larger cations, since they were considered to have a smaller "effective" radius (including their hydration shell), and thus could be more concentrated in the Helmholtz plane. 
Beyond a continuum description, atomic level elucidations on the cation effect have also been pursued; despite that it is often called a Helmholtz "plane", there is no actual planar object at the atomic scale. In contrast to the continuum explanation, Chen et al. and Resasco et al. proposed that cation stabilization via the EDL field is a more localized effect, driven by cations that directly interact with

5 the adsorbates. ${ }^{24,25}$ Very recently, a more direct involvement of cations in the first reduction step of the $\mathrm{CO}_{2} \mathrm{RR}$ was come up with by Monteiro et al. A possibility of cation complexation to the $\mathrm{CO}_{2}^{-}$ intermediate was suggested based on their ab initio molecular dynamics (AIMD) simulation results. ${ }^{14}$ Furthermore, they reported experimental results using scanning electrochemical microscopy (SECM) that the $\mathrm{CO}_{2} \mathrm{RR}$ becomes possible only if alkali metal cations exist in solution.

In a continuum of the recent efforts to unveil the cation effect, here we have theoretically and experimentally investigated the cation-controlled mechanism of electrochemical $\mathrm{CO}_{2} \mathrm{RR}$ with reflecting more practical electrolysis conditions, i.e., simulation under an actual concentration of electrolyte for a long-enough time and experiments with a flow-type device. We first confirmed that alkali metal cations co-catalyze the first reduction step of the $\mathrm{CO}_{2} \mathrm{RR}$ through cation-coupled electron transfer (CCET) in agreement with the finding of Monteiro et al. ${ }^{14}$ We further disclosed that the cation effect is a local colligative property, i.e., the local cation concentration at the EDL mainly governs the $\mathrm{CO}_{2} \mathrm{RR}$ kinetics, regardless of the cation species. By elucidating the atomic origin of the cation effect, our CCET-based mechanism suggests a future research direction for improving the $\mathrm{CO}_{2} \mathrm{RR}$ electrocatalysis by tailoring the catalyst-electrolyte interphase.

\section{RESULTS AND DISCUSSION}

\section{Local environment of $\mathrm{CO}_{2}$ and $\mathrm{COOH}$ adsorbates}

Our recently developed first-principles-based multiscale simulation, DFT in classical explicit solvents (DFT-CES), ${ }^{26}$ allows the DFT calculations with including all molecular constituents of the electrolyte 
the local environment surrounding a bent $\mathrm{CO}_{2}$ adsorbate at the atomic level. Over the course of the DFT-CES iterations, we found that one $\mathrm{K}^{+}$is coordinated to the bent $\mathrm{CO}_{2}$ over the entire simulation time of $5 \mathrm{~ns}$ (Figure 1a) in a bidentate form (where $\mathrm{K}^{+}-\mathrm{O}$ distance is $c a .2 .5 \AA$ ), which helps polarize an additional electron to the $\mathrm{CO}_{2}$ adsorbate, leading its partial charge to be -0.8 e (Figure 1b), consistent to the previous AIMD simulation result. ${ }^{14}$ Thus, the bent $\mathrm{CO}_{2}$ adsorbate needs to be more appropriately labeled as $* \mathrm{CO}_{2}{ }^{-} \cdots \mathrm{K}^{+}$(see left panel of Figure 1c for its characteristic local environment). This is notable since the possibility of cation coupling to the $\mathrm{CO}_{2}$ adsorbate, which was identified by the previous AIMD simulation using the small simulation cell performed for a short time of $2 \mathrm{ps},{ }^{14}$ is confirmed from our DFT-CES simulation investigating 5-ns dynamics of actual composition of electrolyte (including both $\mathrm{K}^{+}$and $\mathrm{HCO}_{3}{ }^{-}$) (Figure S1). In addition, the formation of ${ }^{*} \mathrm{CO}_{2}{ }^{-} \cdots \mathrm{K}^{+}$is an electrochemical step with a potential-dependent thermodynamic barrier (left panel of Figure 1d).

To seek for the reaction path for the subsequent proton transfer, we further investigated the local environment surrounding a $\mathrm{COOH}$ adsorbate $\left({ }^{*} \mathrm{COOH}\right)$ using the DFT-CES (right panel of Figure 1c). Near the ${ }^{*} \mathrm{COOH}$, our simulation revealed that one $\mathrm{K}^{+}$is coordinated to the $\mathrm{O}(=\mathrm{C})$ in a monodentate form, and one $\mathrm{OH}^{-}$is coordinated to the $\mathrm{HO}$ of $* \mathrm{COOH}$ over the entire simulation time of $5 \mathrm{~ns}$ (Figure S2). In addition, a water molecule bridges the $\mathrm{K}^{+}$and $\mathrm{OH}^{-}$via hydrogen-bond network while exchanging the position with another water molecule during the simulation. Considering the water structure near the ${ }^{*} \mathrm{CO}_{2}{ }^{-} \cdots \mathrm{K}^{+}$, where around two water molecules (which are not strongly bound) tend to bridge the $\mathrm{K}^{+}$and the terminal $\mathrm{O}$ of $* \mathrm{CO}_{2}^{-}$during the simulation, we conceive that the intervened water molecule between $\mathrm{K}^{+}$and ${ }^{*} \mathrm{CO}_{2}{ }^{-}$will readily transfer a proton to the terminal oxygen of ${ }^{*} \mathrm{CO}_{2}{ }^{-}$. Indeed, our climbing image nudged elastic band (CI-NEB) calculation shows that the structural rearrangement from the bidentate form to the monodentate form is energetically downhill by $0.6 \mathrm{eV}$, suggesting a cation-facilitated protolysis path of water after the cation coupling to $* \mathrm{CO}_{2}{ }^{-}$(right panel of Figure 1d and Figure S3). ${ }^{27}$

\section{Cation-coupled electron transfer}


Our atomically resolved elucidations on the electrolyte structure suggest that the coordinating affinity of $\mathrm{K}^{+}$to ${ }^{*} \mathrm{CO}_{2}^{-}$is a key parameter, which can determine the kinetics of the first reduction step of the $\mathrm{CO}_{2} \mathrm{RR}$. To unravel the role of cation more clearly, we investigated the $\mathrm{CO}_{2} \mathrm{RR}$ activity of polycrystalline Ag electrode in an electrochemical flow cell (Figures $\mathbf{S 4}$ and S5). ${ }^{6,28}$ The $\mathrm{CO}_{2}$-to-CO conversion was measured in various concentrations of $\mathrm{KOH}$ electrolytes $(0.01-10 \mathrm{M})$ (Figure 2 and S6). The $j_{\mathrm{CO}}$ versus potential curves reveal that their Tafel slopes are $120-130 \mathrm{mV} \mathrm{dec}^{-1}$, indicating the first electron transfer step to be the RDS. ${ }^{29}$ On both standard hydrogen electrode (SHE) and reversible hydrogen electrode (RHE) scales, the $j_{\mathrm{CO}}$ shows considerable deviations in their polarization curves as the $\mathrm{KOH}$ concentrations are varied (Figure $2 \mathbf{a}-\mathbf{b}$ ). In both reference scales, the $\mathrm{CO}_{2} \mathrm{RR}$ activity is enhanced by increasing $\mathrm{KOH}$ concentration. However, this implies that the $\mathrm{CO}_{2} \mathrm{RR}$ kinetics does not simply depend on the electrode potential (i.e., $*+\mathrm{CO}_{2}+\mathrm{e}^{-} \rightarrow{ }^{*} \mathrm{CO}_{2}^{-}$), nor does its RDS accompany the PCET step (i.e., * $\left.+\mathrm{CO}_{2}+\mathrm{H}^{+}+\mathrm{e}^{-} \rightarrow{ }^{*} \mathrm{COOH}\right) .{ }^{30}$ Hence, the inconsistency led us to reasonably account for the RDS to be a coupled mechanism with other species, such as $\mathrm{K}^{+}$, as predicted by our simulation results. Therefore, we re-plotted the polarization curves with respect to an alkali metal cation activity-corrected electrode (ACE) scale (Figure 2c), which is defined here as $E_{\mathrm{ACE}}=E_{\mathrm{SHE}}-0.059 \times$ $\log \left[\mathrm{M}^{+}\right]$, where $\mathrm{M}^{+}$denotes an alkali metal cation. ${ }^{31}$ This plot identifies a collapse of the $j_{\text {co }}$ polarization curves independent of the $\mathrm{KOH}$ electrolyte concentration, corresponding to a Nernstian potential shift of $c a .60 \mathrm{mV}$ per $\log \left[\mathrm{K}^{+}\right]$on the SHE scale. The same conclusion can also be obtained using $0.01 \mathrm{M}$ $\mathrm{KOH}+0-0.495 \mathrm{M} \mathrm{K}_{2} \mathrm{CO}_{3}$ electrolytes (Figures $\mathbf{S 7}$ and S8), in which only the $\mathrm{K}^{+}$concentration was controlled, whereas electrolyte $\mathrm{pH}$ was almost untouched (Figure S9). Therefore, it can be concluded that changes in the $\mathrm{CO}_{2} \mathrm{RR}$ kinetics are primarily governed by the $\mathrm{K}^{+}$activity, rather than electrolyte $\mathrm{pH}^{32,33}$

All our findings from multiscale simulations and flow-cell experiments strongly support the following reaction mechanism for the $\mathrm{CO}_{2} \mathrm{RR}$ on the $\mathrm{Ag}$ electrode, which is in line with the recent proposition based on the results from AIMD simulations and SECM experiments. ${ }^{14}$

$$
*+\mathrm{CO}_{2}(\mathrm{~g})+\mathrm{M}^{+}+\mathrm{e}^{-} \rightarrow * \mathrm{CO}_{2}^{-} \cdots \mathrm{M}^{+}
$$




$$
\begin{aligned}
& { }^{* \mathrm{CO}_{2}}{ }^{-} \cdots \mathrm{M}^{+}+\mathrm{H}_{2} \mathrm{O} \rightarrow{ }^{*} \mathrm{COOH} \cdots \mathrm{M}^{+}+\mathrm{OH}^{-} \\
& * \mathrm{COOH} \cdots \mathrm{M}^{+}+\mathrm{e}^{-} \rightarrow * \mathrm{CO}+\mathrm{M}^{+}+\mathrm{OH}^{-} \\
& * \mathrm{CO} \rightarrow \mathrm{CO}(\mathrm{g})+*
\end{aligned}
$$

where (R1) is the CCET step, which is the RDS, while the proton transfer step (R2) is considered to be 5 fast, as shown in the previous CI-NEB calculation (Figure S3).

Reaction kinetic study is another strong method to verify the reaction mechanism. ${ }^{34}$ Following the above CCET-based mechanism, the overall rate of the $\mathrm{CO}_{2} \mathrm{RR}$ can be written as follows.

$$
\text { rate }=k P_{\mathrm{CO}_{2}}\left[\mathrm{M}^{+}\right] \exp \left(-\frac{\Delta G_{(\mathrm{R} 1)}^{\ddagger}-\alpha F E_{\mathrm{SHE}}}{R T}\right)
$$

where $k, P_{\mathrm{CO}_{2}},\left[\mathrm{M}^{+}\right], \Delta G_{(\mathrm{R} 1)}^{\ddagger}, \alpha$, and $F$ are the rate constant, $\mathrm{CO}_{2}$ partial pressure, cation concentration, activation energy of (R1) at $E_{\mathrm{SHE}}=0 \mathrm{~V}$, charge-transfer coefficient, and Faradaic constant, respectively. As the electrochemical reaction occurs at the interface, its rate needs to be governed by the local cation concentration at the EDL; ${ }^{35}$ however, it is not straightforwardly measurable or even defined. ${ }^{36}$ Thus, we hypothesize that the excess cations at the EDL region to compensate the electrode surface charge will participate in the reaction, and the $\left[\mathrm{M}^{+}\right]$will be equal to or (at least) proportional to the magnitude of the electrode surface charge density, ${ }^{35}|\sigma|$. If our hypothesis is correct, this should lead to a first-order dependence of the $\mathrm{CO}_{2} \mathrm{RR}$ rate on $|\sigma|$, and thus a linear relationship between $|\sigma|$ and $j_{\mathrm{CO}}$ is expected when $j_{\mathrm{CO}}$ is measured at the same potential on the SHE scale and the same $P_{\mathrm{CO}_{2}}$.

Then, we measured the differential capacitance $\left(C_{\text {diff }}\right)$ of the Ag electrode in each electrolyte using staircase potentio electrochemical impedance spectroscopy (SPEIS). The $|\sigma|$ at a certain potential ( $\left.E^{\prime}\right)$ can be estimated by integrating $C_{\text {diff }}$ from the potential at point of zero charge $\left(E_{\mathrm{PZC}}\right.$; Figure S10) to the $E^{\prime} \cdot 37-40$

$$
|\sigma|=\left|\int_{E_{\mathrm{PZC}}}^{E^{\prime}} C_{\mathrm{diff}} \mathrm{d} E\right|
$$

The results show an increase in $C_{\text {diff }}$ when increasing the $\mathrm{K}^{+}$concentration in the electrolyte (Figure 
S11), consequently leading to a magnified $|\sigma|$ on the Ag electrode. A correlation between $|\sigma|$ and $j_{\mathrm{CO}}$ at $-1.3 \mathrm{~V}_{\mathrm{SHE}}$ identifies a linear function with a slope of unity on a $\log$ scale (Figure 3 ). Hence, the firstorder dependence of $j_{\mathrm{CO}}$ on $|\sigma|$ was verified, evidencing the CCET-governing step described by the mechanism (R1).

\section{Cation effect as a local colligative property}

In the context of the CCET-based mechanism for the $\mathrm{CO}_{2} \mathrm{RR}$, our question is then oriented to unveil the underlying fundamental origin of the cation effect, i.e., $\mathrm{CO}_{2} \mathrm{RR}$ activity dependency on alkali metal cation species. The $\mathrm{CO}_{2}$ electrolysis results, measured in various alkali metal carbonate electrolytes (set to $0.05 \mathrm{M}$ ), revealed the $\mathrm{CO}_{2} \mathrm{RR}$ activity trend of $\mathrm{Cs}^{+}>\mathrm{Rb}^{+}>\mathrm{K}^{+}>\mathrm{Na}^{+}>\mathrm{Li}^{+}$(Figure S12). This trend agrees well with other results reported in the literature. ${ }^{14,16,23}$ To identify whether cations other than $\mathrm{K}^{+}$ can also co-catalyze the $\mathrm{CO}_{2} \mathrm{RR}$ via a formation of the $* \mathrm{CO}_{2}{ }^{-} \cdots \mathrm{M}^{+}$intermediate, the $C_{\text {diff }}$ of Ag electrode was also evaluated in those electrolytes (Figure S13). The results show a decrease in the $C_{\text {diff }}$ value in the order of $\mathrm{Cs}^{+}>\mathrm{Rb}^{+}>\mathrm{K}^{+}>\mathrm{Na}^{+}>\mathrm{Li}^{+}$, the trend of which corresponds to that of their $\mathrm{CO}_{2} \mathrm{RR}$ activity. The relationship between the estimated $|\sigma|$ and $j_{\mathrm{CO}}$ values at $-1.3 \mathrm{~V}_{\mathrm{SHE}}$ was also greatly fit with a linear fitting line, which was derived from the data for various $\mathrm{K}^{+}$-based electrolytes (Figure 3). This result thus infers that the activity dependency of the $\mathrm{CO}_{2} \mathrm{RR}$ on alkali metal cations, namely the cation effects, is primarily attributed to variations in the amount of excess cations at the EDL region and consequently to the different kinetics based on the mechanism (R1). Thus, $k$ is independent of the cation species, implying that the cation effect on the $\mathrm{CO}_{2} \mathrm{RR}$ is a local colligative effect.

The last but not the least question we are now faced with is why larger cation, such as $\mathrm{Cs}^{+}$, accumulates more than smaller one at the EDL. However, a full understanding of the EDL structure and energetics is extremely challenging and still remains an open question. ${ }^{36}$ Therefore, possible rationales will be discussed hereafter on the basis of computational results. On the one hand, by analyzing the energetics from the AIMD simulation results, Monteiro et al. found that a relative stability of the cation at the electrochemical interface to that at the bulk is enhanced for larger cations. ${ }^{14}$ Such an explanation 
based on the thermodynamic driving force provides a good rationale for answering why larger cations can accumulate more at the EDL. However, the energy difference of ca. $1.8 \mathrm{eV}$ between $\mathrm{Li}^{+}$and $\mathrm{Cs}^{+}$ suggested in the previous study ${ }^{14}$ is converted into the Boltzmann population ratio on the order of $10^{30}$ at room temperature, which is considered too large.

On the other hand, from our DFT-CES simulations, where $|\sigma|$ (i.e., the simulation control parameter) is maintained to be same, we found that the interfacial potential drop across the EDL (which determines the electrochemical potential) decreases in the order of $\mathrm{Li}^{+}>\mathrm{Na}^{+}>\mathrm{K}^{+}>\mathrm{Cs}^{+}$for the $0.1 \mathrm{M}$ electrolytes (Figures 4a and S14). This result implies that, to achieve a same electrochemical potential (i.e., the experimental control parameter), inducing more cathodic polarization is required for larger cations, which leads the $|\sigma|$ to show the trend of $\mathrm{Li}^{+}<\mathrm{Na}^{+}<\mathrm{K}^{+}<\mathrm{Cs}^{+}$when measured at the same potential. When only a minimal number of cations are included to compensate for the electrode surface charge (without including anions), for comparison, the interfacial potential drop shows virtually no dependence on the cation species (Figures 4a and S14). This indicates a cooperative role of cations and anions in determining the potential drop across the interface.

Smaller cations usually demonstrate stronger ion-pairing, ${ }^{41}$ which is often ascribed to their hardness. ${ }^{42-44}$ Our simulation results also demonstrate the formation of fewer contact ion-pairs for larger cations (Figure S15). The loosely bound cation-anion-pairs, which are found in the electrolyte with larger cations, can better screen the charged electrode than the tightly bound ones, which are found in the electrolyte with smaller cations (Figure $\mathbf{4 b}-\mathbf{c}$ ), and thus increase $C_{\text {diff }}$ as well as $|\sigma|$.

In summary, our present work affirms that the CCET - coupling of alkali metal ion to the key intermediate of $* \mathrm{CO}_{2}{ }^{-}$- is the $\mathrm{RDS}$ of the $\mathrm{CO}_{2} \mathrm{RR}$. It is not only demonstrated from our advanced simulation for the electrochemical interface (under more realistic conditions), but also experimentally verified from the Nernstian potential shift depending on the cation concentration as well as the kinetic studies. Furthermore, the cation effect is found to be a local colligative property, which originates predominantly from the difference in the local cation concentration at the EDL, not from the difference in the nature of chemical interaction between cation and intermediate. Consequently, next discussion 
for further improving the $\mathrm{CO}_{2} \mathrm{RR}$ electrolysis is related to identifying strategies for maximizing the local cation concentration at the EDL. Although this motivates numerous other studies, since the EDL engineering is highly complicated as multiple components and their mutual interactions are convoluted, ${ }^{36}$ our finding emphasizes the importance of controlling the cation-anion-pairs. To prove the suggested concept, we demonstrated that the local cation concentration can be modulated by changing the anion species at the EDL, which regulates the $\mathrm{CO}_{2} \mathrm{RR}$ kinetics up to three-folds (Figure S16). We thus envisage that our present elucidation of the CCET mechanism and the cation effect will trigger many other ideas to optimize the EDL characteristics for improving the $\mathrm{CO}_{2} \mathrm{RR}$ electrolysis. 


\section{METHODS}

\section{DFT-CES simulations}

Our mean-field quantum mechanics/molecular mechanics (QM/MM) multiscale simulation, namely, DFT-CES ${ }^{26}$, is implemented in our in-house code that combines the Quantum ESPRESSO ${ }^{45}$ density 5 functional theory simulation engine and LAMMPS ${ }^{46}$ molecular dynamics simulation engine. Computational details can be found in the Supplementary Note 1.

\section{Electrochemical measurements}

All electrochemical studies were conducted with a VMP-300 potentiostat (Bio-Logic). The $\mathrm{CO}_{2} \mathrm{RR}$ electrolysis was performed in an H-type electrochemical flow cell (Figure S4), in which an Ag working electrode and a saturated $\mathrm{Ag} / \mathrm{AgCl}$ reference electrode (RE-16, EC-Frontier) were physically separated from a Ni-foam counter electrode (MTI Korea) by an anion exchange membrane (AEM; fab-pk-130, Fumasep). The Ag working electrode was prepared by deposition of $\mathrm{Ag}$ (99.99\%) onto polytetrafluoroethylene (PTFE) membrane as a gas diffusion electrode (GDE) with a pore size of 450 nm using an e-beam evaporator (Ulvac Inc.) at a constant deposition rate of $3 \AA \mathrm{s}^{-1}$ at a vacuum level of $10^{-6}-10^{-7}$ Torr. The preparation of the Ag-PTFE working electrode was confirmed by scanning electron microscope (SEM; Verios 5 UC instrument, Thermo Fisher Scientific) and the X-ray diffraction (XRD; EMPyrean, PANalytical). The XRD pattern was obtained at an accelerating voltage of $40 \mathrm{kV}$ and a current of $30 \mathrm{~mA}$ with a scan rate of $14.1^{\circ} \mathrm{min}^{-1}$. The electrolytes were prepared using deionized water $\left(\geq 18.2 \mathrm{M} \Omega\right.$, Arium ${ }^{\circledR}$ mini, Sartorius) and various alkali metal salts (all supplied by SigmaAldrich): $\mathrm{KOH}$ (99.99\% trace metal basis); $\mathrm{K}_{2} \mathrm{CO}_{3}$ (99.995\% trace metal basis); $\mathrm{Li}_{2} \mathrm{CO}_{3}(99.999 \%$ trace metal basis); $\mathrm{Na}_{2} \mathrm{CO}_{3}$ (99.95-100.05\% dry basis); $\mathrm{Rb}_{2} \mathrm{CO}_{3}$ (99.8\% trace metal basis); $\mathrm{Cs}_{2} \mathrm{CO}_{3}(99.995 \%$ trace metal basis); $\mathrm{KClO}_{4}\left(99.99 \%\right.$ trace metal basis); and $\mathrm{K}_{2} \mathrm{SO}_{4}(99.0 \%)$. The electrolyte continuously flowed into both anode and cathode compartments of the electrochemical cell with a flow rate of $5 \mathrm{~mL}$ $\min ^{-1} . \mathrm{CO}_{2}$ gas $(99.9 \%)$ was introduced at the back of the Ag-PTFE working electrode at a constant rate 
of $20 \mathrm{~mL} \mathrm{~min}{ }^{-1}$. The reference electrode was calibrated against a $\mathrm{Pt}$ electrode in $\mathrm{H}_{2}$-saturated electrolytes to correctly convert potentials to the RHE scale prior to every single measurement. The $\mathrm{CO}_{2} \mathrm{RR}$ electrolysis was progressed by a chronoamperometry $(\mathrm{CA})$ for $1 \mathrm{~h}$ at certain potentials. The gas products were analyzed using an online gas chromatograph (YL6500 GC, YL Instrument) equipped with a thermal conductivity detector (TCD) and a flame ionization detector (FID). A Carboxen-1000 column (12390-U, Supelco) was used for both TCD and FID, and Ar (99.999\%) was used as a reference gas. All polarization curves measured during the $\mathrm{CO}_{2} \mathrm{RR}$ electrolysis were compensated using a manual IR compensation (MIR, 85\%) program.

The $C_{\text {diff }}$ of the $\mathrm{Ag}$ electrode was measured using a conventional three-electrode system. A polycrystalline Ag foil (99.998\%, Alfa Aesar), a graphite rod, and a saturated $\mathrm{Ag} / \mathrm{AgCl}$ electrode were employed as the working, counter, and reference electrodes, respectively. Prior to every single measurement, the $\mathrm{Ag}$ electrode was chemically polished using the following procedure. The $\mathrm{Ag}$ electrode was first immersed in a solution mixture of $0.3 \mathrm{M} \mathrm{KCN}\left(\geq 96 \%\right.$, Sigma-Aldrich) and $\mathrm{H}_{2} \mathrm{O}_{2}$ (29-32\%, Alfa Aesar) with a volume ratio of $1.5: 1$ for $3 \mathrm{~s}$, during which gas was vigorously evolved, and thereafter it was exposed to air for another $3 \mathrm{~s}$. The Ag electrode was subsequently soaked in a 0.55 M KCN solution until the gas evolution ceased, and it was thoroughly washed with DI water. A highly reflective surface was obtained after repeating the chemical polishing procedure 10 times. The $\mathrm{Ag}$ electrode surface was protected by ultrapure water before it was transferred to the electrochemical cell. The $C_{\text {diff }}$ was measured by SPEIS in a potential range from -1.5 to $0.2 \mathrm{~V}_{\text {SHE }}$ with a frequency of $20 \mathrm{~Hz}$ and a potential amplitude of $10 \mathrm{mV}$. The Ohmic loss was compensated during the SPEIS experiments. Identical electrolytes for the $\mathrm{CO}_{2} \mathrm{RR}$ electrolysis were used for the $C_{\text {diff }}$ measurements. In addition, the $E_{\text {PZC }}$ was separately measured in a highly diluted $2 \mathrm{mM} \mathrm{NaF}$ solution and was defined as the potential where the smallest $C_{\text {diff }}$ value was observed. The $|\sigma|$ at a certain potential ( $E^{\prime} v s$. SHE) could be estimated by integrating the $C_{\text {diff }}$ from the $E_{\mathrm{PZC}}$ to the $E$ '.

$$
|\sigma|=\left|\int_{E_{\mathrm{PZC}}}^{E^{\prime}} C_{\mathrm{diff}}(E) \mathrm{d} E\right|
$$




\section{DATA AVAILABILITY}

All data is available in the main text or the Supplementary Information.

\section{CODE AVAILABILITY}

5 The DFT-CES code has been deposited in the github database without accession code [https://github.com/SeungJay].

\section{REFERENCES}

1. Lin, S. et al. Covalent organic frameworks comprising cobalt porphyrins for catalytic $\mathrm{CO}_{2}$ reduction in water. Science 349, 1208-1213 (2015).

2. Gao, S. et al. Partially oxidized atomic cobalt layers for carbon dioxide electroreduction to liquid fuel. Nature 529, 68-71 (2016).

3. Huang, J. E. et al. $\mathrm{CO}_{2}$ electrolysis to multicarbon products in strong acid. Science 372, 1074-1078 (2021).

4. Nitopi, S. et al. Progress and perspectives of electrochemical $\mathrm{CO}_{2}$ reduction on copper in aqueous electrolyte. Chem. Rev. 119, 7610-7672 (2019).

5. Kortlever, R., Shen, J., Schouten, K. J. P., Calle-Vallejo, F. \& Koper, M. T. M. Catalysts and reaction pathways for the electrochemical reduction of carbon dioxide. J. Phys. Chem. Lett. 6, 4073-4082 (2015).

6. Dinh, C.-T. et al. $\mathrm{CO}_{2}$ electroreduction to ethylene via hydroxide-mediated copper catalysis at an abrupt interface. Science 360, 783-787 (2018).

7. Kim, $\mathrm{Y}$. et al. Time-resolved observation of $\mathrm{C}-\mathrm{C}$ coupling intermediates on $\mathrm{Cu}$ electrodes for selective electrochemical $\mathrm{CO}_{2}$ reduction. Energy Environ. Sci. 13, 4301-4311 (2020).

8. Back, S., Yeom, M. S. \& Jung, Y. Active sites of $\mathrm{Au}$ and $\mathrm{Ag}$ nanoparticle catalysts for $\mathrm{CO}_{2}$ electroreduction to CO. ACS Catal. 5, 5089-5096 (2015). 
9. Hori, Y. in Modern aspects of electrochemistry. Vol. 42, 89-189 (Springer, 2008).

10. Hori, Y., Wakebe, H., Tsukamoto, T. \& Koga, O. Electrocatalytic process of CO selectivity in electrochemical reduction of $\mathrm{CO}_{2}$ at metal electrodes in aqueous media. Electrochim. Acta 39, 1833-1839 (1994).

5 11. Lu, Q. et al. A selective and efficient electrocatalyst for carbon dioxide reduction. Nat. Commun. $\mathbf{5}$, $3242(2014)$.

12. Dunwell, M. et al. Examination of near-electrode concentration gradients and kinetic impacts on the electrochemical reduction of $\mathrm{CO}_{2}$ using surface-enhanced infrared spectroscopy. ACS Catal. 8 , 3999-4008 (2018).

13. Ringe, S. et al. Double layer charging driven carbon dioxide adsorption limits the rate of electrochemical carbon dioxide reduction on gold. Nat. Commun. 11, 33 (2020).

14. Monteiro, M. C. O. et al. Absence of $\mathrm{CO}_{2}$ electroreduction on copper, gold and silver electrodes without metal cations in solution. Nat. Catal. 4, 654-662 (2021).

15. Murata, A. \& Hori, Y. Product Selectivity Affected by Cationic Species in Electrochemical Reduction on $\mathrm{CO}_{2}$ and $\mathrm{CO}$ at a Cu Electrode. Bull. Chem. Soc. Jpn. 64, 123-127 (1991).

16. Singh, M. R., Kwon, Y., Lum, Y., Ager, J. W. \& Bell, A. T. Hydrolysis of electrolyte cations enhances the electrochemical reduction of $\mathrm{CO}_{2}$ over $\mathrm{Ag}$ and Cu. J. Am. Chem. Soc. 138, 13006$13012(2016)$.

17. Lim, H.-K. et al. Embedding covalency into metal catalysts for efficient electrochemical conversion of $\mathrm{CO}_{2} . J$. Am. Chem. Soc. 136, 11355-11361 (2014).

18. Kim, C. et al. Achieving selective and efficient electrocatalytic activity for $\mathrm{CO}_{2}$ reduction using immobilized silver nanoparticles. J. Am. Chem. Soc. 137, 13844-13850 (2015).

19. Kim, K.-S., Kim, W. J., Lim, H.-K., Lee, E. K. \& Kim, H. Tuned chemical bonding ability of Au at grain boundaries for enhanced electrochemical $\mathrm{CO}_{2}$ reduction. ACS Catal. 6, 4443-4448 (2016).

20. Kim, C. et al. Insight into electrochemical $\mathrm{CO}_{2}$ reduction on surface-molecule-mediated $\mathrm{Ag}$ nanoparticles. ACS Catal. 7, 779-785 (2017).

21. Wuttig, A., Yaguchi, M., Motobayashi, K., Osawa, M. \& Surendranath, Y. Inhibited proton transfer 
enhances Au-catalyzed $\mathrm{CO}_{2}$-to-fuels selectivity. PNAS 113, E4585-E4593 (2016).

22. Zhang, B. A., Ozel, T., Elias, J. S., Costentin, C. \& Nocera, D. G. Interplay of Homogeneous Reactions, Mass Transport, and Kinetics in Determining Selectivity of the Reduction of $\mathrm{CO}_{2}$ on Gold Electrodes. ACS Cent. Sci. 5, 1097-1105 (2019).

23. Ringe, S. et al. Understanding cation effects in electrochemical $\mathrm{CO}_{2}$ reduction. Energy Environ. Sci. 12, 3001-3014 (2019).

24. Chen, L. D., Urushihara, M., Chan, K. \& Nørskov, J. K. Electric field effects in electrochemical $\mathrm{CO}_{2}$ reduction. ACS Catal. 6, 7133-7139 (2016).

25. Resasco, J. et al. Promoter effects of alkali metal cations on the electrochemical reduction of carbon dioxide. J. Am. Chem. Soc. 139, 11277-11287 (2017).

26. Lim, H.-K., Lee, H. \& Kim, H. A seamless grid-based interface for mean-field QM/MM coupled with efficient solvation free energy calculations. J. Chem. Theory Comput. 12, 5088-5099 (2016).

27. Shi, C., O’Grady, C. P., Peterson, A. A., Hansen, H. A. \& Nørskov, J. K. Modeling $\mathrm{CO}_{2}$ reduction on Pt(111). Phys. Chem. Chem. Phys. 15, 7114 (2013).

28. Dinh, C.-T., García de Arquer, F. P., Sinton, D. \& Sargent, E. H. High rate, selective, and stable electroreduction of $\mathrm{CO}_{2}$ to $\mathrm{CO}$ in basic and neutral media. ACS Energy Lett. 3, 2835-2840 (2018).

29. Bard, A. J. \& Faulkner, L. R. Kinetics of Electrode Reactions. In Electrochemical methods: fundamentals and applications. (John Wiley \& Sons, Inc., 2001).

30. Jerkiewicz, G. Standard and reversible hydrogen electrodes: theory, design, operation, and applications. ACS Catal. 10, 8409-8417 (2020).

31. Bard, A. J. \& Faulkner, L. R. Potentials and Thermodynamics of Cells. In Electrochemical methods: fundamentals and applications. (John Wiley \& Sons, Inc., 2001).

32. Liu, M. et al. Enhanced electrocatalytic $\mathrm{CO}_{2}$ reduction via field-induced reagent concentration. Nature 537, 382-386 (2016).

33. Monteiro, M. C. O., Philips, M. F., Schouten, K. J. P. \& Koper, M. T. M. Efficiency and selectivity of $\mathrm{CO}_{2}$ reduction to $\mathrm{CO}$ on gold gas diffusion electrodes in acidic media. Nat. Commun. 12, 4943 (2021). 
34. McQuarrie, D. A. \& Simon, J. D. Physical chemistry: a molecular approach. (University Science Books, 1997).

35. Goyal, A. \& Koper, M. T. M. The interrelated effect of cations and electrolyte $\mathrm{pH}$ on the hydrogen evolution reaction on gold electrodes in alkaline media. Angew. Chem. Int. Ed. 60, 13452-13462 (2021).

36. Magnussen, O. M. \& Groß, A. Toward an atomic-scale understanding of electrochemical interface structure and dynamics. J. Am. Chem. Soc. 141, 4777-4790 (2019).

37. Trasatti, S. \& Lust, E. in Modern Aspects of Electrochemistry. Vol. 33, 1-198 (Kluwer Academic / Plenum Publishers, 1999).

38. Valette, G. Double layer on silver single-crystal electrodes in contact with electrolytes having anions which present a slight specific adsorption Part I. The (110) face. J. Electroanal. Chem. 122, 285-297 (1981).

39. Valette, G. Double layer on silver single-crystal electrodes in contact with electrolytes having anions which present a slight specific adsorption Part II. The (100) face. J. Electroanal. Chem. 138, $37-54(1982)$

40. Valette, G. Double layer on silver single-crystal electrodes in contact with electrolytes having anions which present a slight specific adsorption Part III. The (111) face. J. Electroanal. Chem. 269, 191-203 (1989).

41. Beierlein, F. R. et al. Carboxylate ion pairing with alkali-metal ions for $\beta$-Lactoglobulin and its role on aggregation and interfacial adsorption. J. Phys. Chem. B 119, 5505-5517 (2015).

42. Lund, M., Jagoda-Cwiklik, B., Woodward, C. E. \& Jungwirth, P. Dielectric interpretation of specificity of ion pairing in water. J. Phys. Chem. Lett. 1, 300-303 (2010).

43. Fennell, C. J., Bizjak, A., Vlachy, V. \& Dill, K. A. Ion pairing in molecular simulations of aqueous alkali halide solutions. J. Phys. Chem. B 113, 6782-6791 (2009).

44. Bian, H. et al. Ion clustering in aqueous solutions probed with vibrational energy transfer. PNAS 108, 4737-4742 (2011).

45. Giannozzi, P. et al. QUANTUM ESPRESSO: a modular and open-source software project for 
quantum simulations of materials. J. Phys.: Condens. Matter 21, 395502 (2009).

46. Plimpton, S. Fast parallel algorithms for short-range molecular dynamics. J. Comput. Phys. 117, 119 (1995).

\section{ACKNOWLEDGEMENTS}

This research was supported by the Samsung Science and Technology Foundation under Project Number SSTF-BA2101-08, the National Research Foundation of Korea (NRF) grant funded by the Korea government (MSIT) (No. 2021R1A5A1030054), the KIST Institutional Program, and the Korea Institute of Science and Technology Information (KISTI) National Supercomputing Center with supercomputing resources including technical support (KSC-2020-CHA-0006).

\section{AUTHOR CONTRIBUTIONS}

H.K. and C.H.C. supervised the project. H.K and S.-J.S. conceived the initial idea. S.-J.S. performed the DFT-CES simulation and analyzed the data. H.C. performed the all the electrochemical experiments.

15 S.R. and D.H.W. contributed to manuscript editing. All authors wrote and revised the manuscript.

\section{COMPETING INTERESTS}

The authors declare no competing interests. 

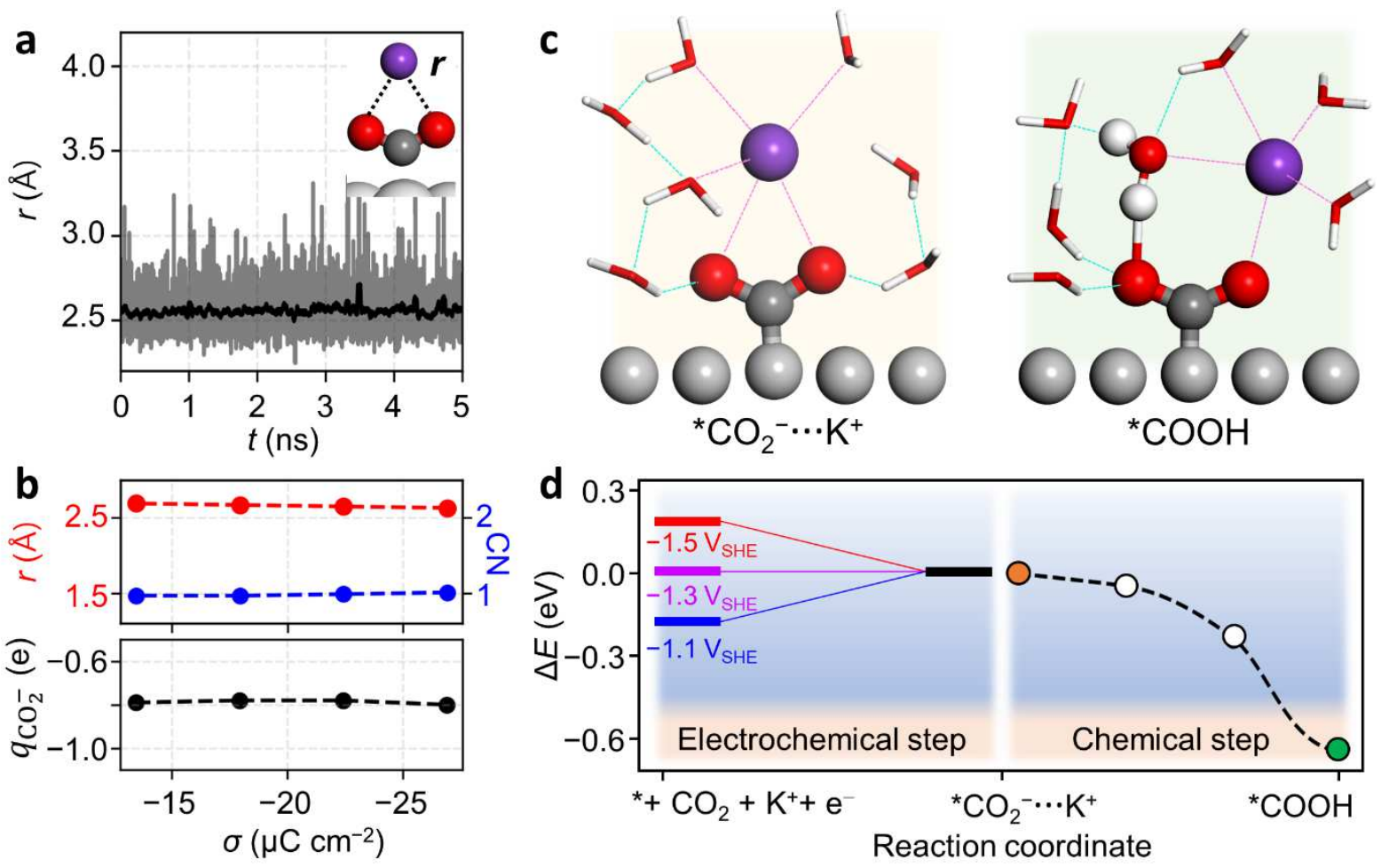

Figure 1. Local environment of the $\mathrm{CO}_{2} R R$. a. Distance $(r)$ between $\mathrm{O}$ of $* \mathrm{CO}_{2}{ }^{-}$and $\mathrm{K}^{+}$with respect to time $(t)$. The black solid line denotes a moving average of the grey line using a $0.05 \mathrm{~ns}$ time window. b. Coordination number $(\mathrm{CN})$ of $* \mathrm{CO}_{2}^{-}$with $\mathrm{K}^{+}$, and the Bader charge of $* \mathrm{CO}_{2}^{-}\left(q_{\mathrm{CO}_{2}^{-}}\right)$as a function of surface charge density, $\sigma$. c. Local solvation structures of the ${ }^{*} \mathrm{CO}_{2}{ }^{-}$and ${ }^{*} \mathrm{COOH}$ sampled from the DFT-CES simulations. Atoms in the quantum mechanics and molecular mechanics regions in the last DFT-CES iteration are represented using balls-and-sticks and sticks, respectively. d. Reaction-energy diagrams to complete the sequential electron (electrochemical step) and proton (chemical step) transfers. Potential-dependent energetics for the electrochemical step were estimated by properly referencing the chemical potentials of the electron and $\mathrm{K}^{+}$(see Supplementary Note 2). The activation energy barrier for the chemical step was calculated using the CI-NEB method. Orange- and green-filled circles denote the reactant and product states, respectively. Their atomic structures were sampled from the DFT-CES calculations and then optimized using DFT. White empty circles indicate NEB data, and $\Delta E$ is the energy difference. 

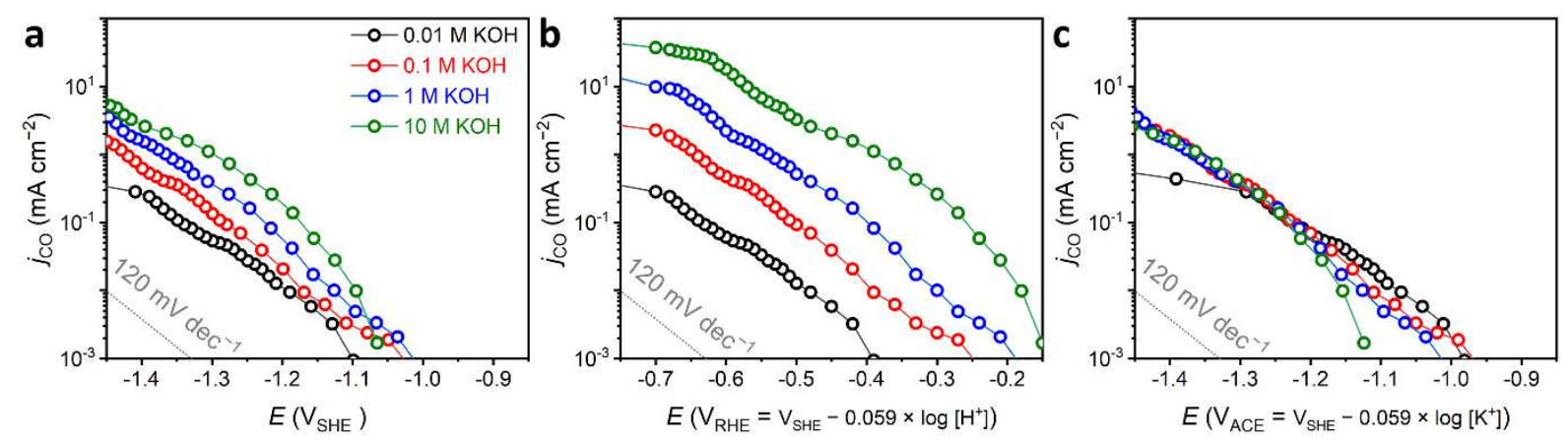

Figure 2. Electrochemical $\mathrm{CO}_{2}$-to-CO conversion on the Ag electrode. Effect of $\mathrm{KOH}$ electrolyte concentration $(0.01-10 \mathrm{M})$ on $j_{\mathrm{CO}}$ versus potential curves measured on the Ag electrode in an electrochemical flow cell. The polarization curves are plotted with respect to the $\mathbf{a}$. SHE, $\mathbf{b}$. RHE $\left(\mathrm{V}_{\mathrm{SHE}}\right.$ $\left.5-0.059 \times \log \left[\mathrm{H}^{+}\right]\right)$, or c. ACE $\left(\mathrm{V}_{\mathrm{SHE}}-0.059 \times \log \left[\mathrm{K}^{+}\right]\right)$scales. The grey lines indicate a Tafel slope (typically plotted as an inverse function of the present polarization curve) of $120 \mathrm{mV} \mathrm{dec}{ }^{-1}$. 


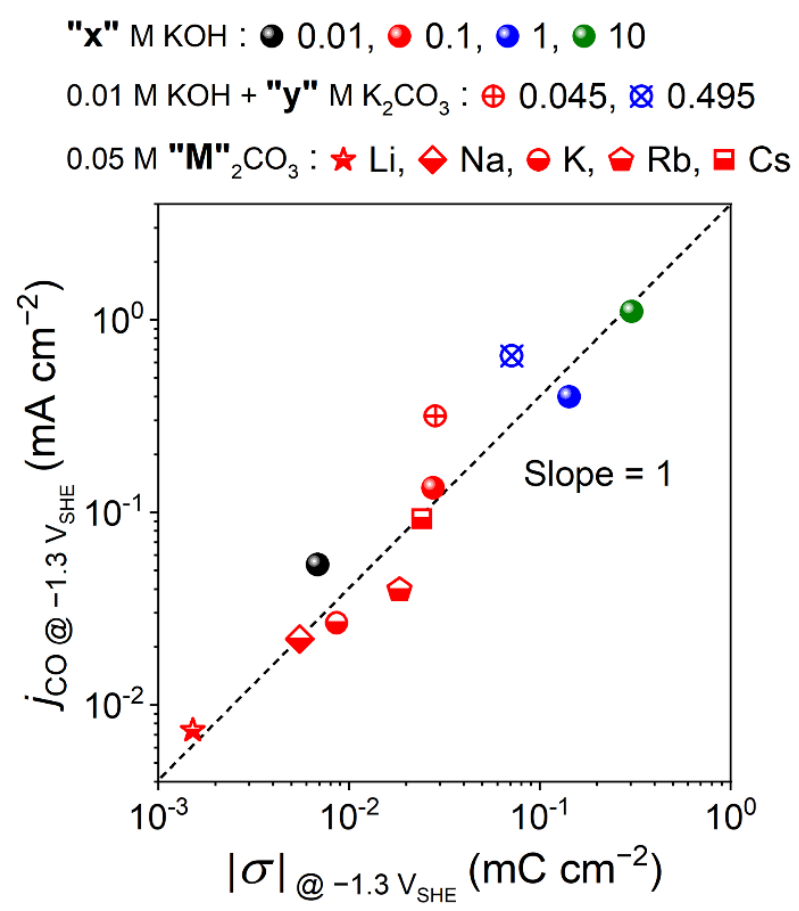

Figure 3. Kinetic study of the $\mathbf{C O}_{2} \mathbf{R R}$ on the Ag electrode. Correlation curve between $|\sigma|$ and $j_{\mathrm{CO}}$ at $-1.3 \mathrm{~V}_{\mathrm{SHE}}$ measured in various electrolytes. The electrolytes used in the present work can be classified into three different categories: $\mathrm{KOH}$ electrolytes with different concentrations (filled circles); $0.01 \mathrm{M}$ $5 \mathrm{KOH}$ electrolytes with additional $\mathrm{K}_{2} \mathrm{CO}_{3}$ salt (crossed circles); and various $0.05 \mathrm{M}$ alkali metal carbonate electrolytes (half-filled symbols). Here, the total concentration of cation in the electrolyte and its species are distinguished by colors and symbol shapes, respectively. A guideline for the slope of one is indicated by a dashed line. 

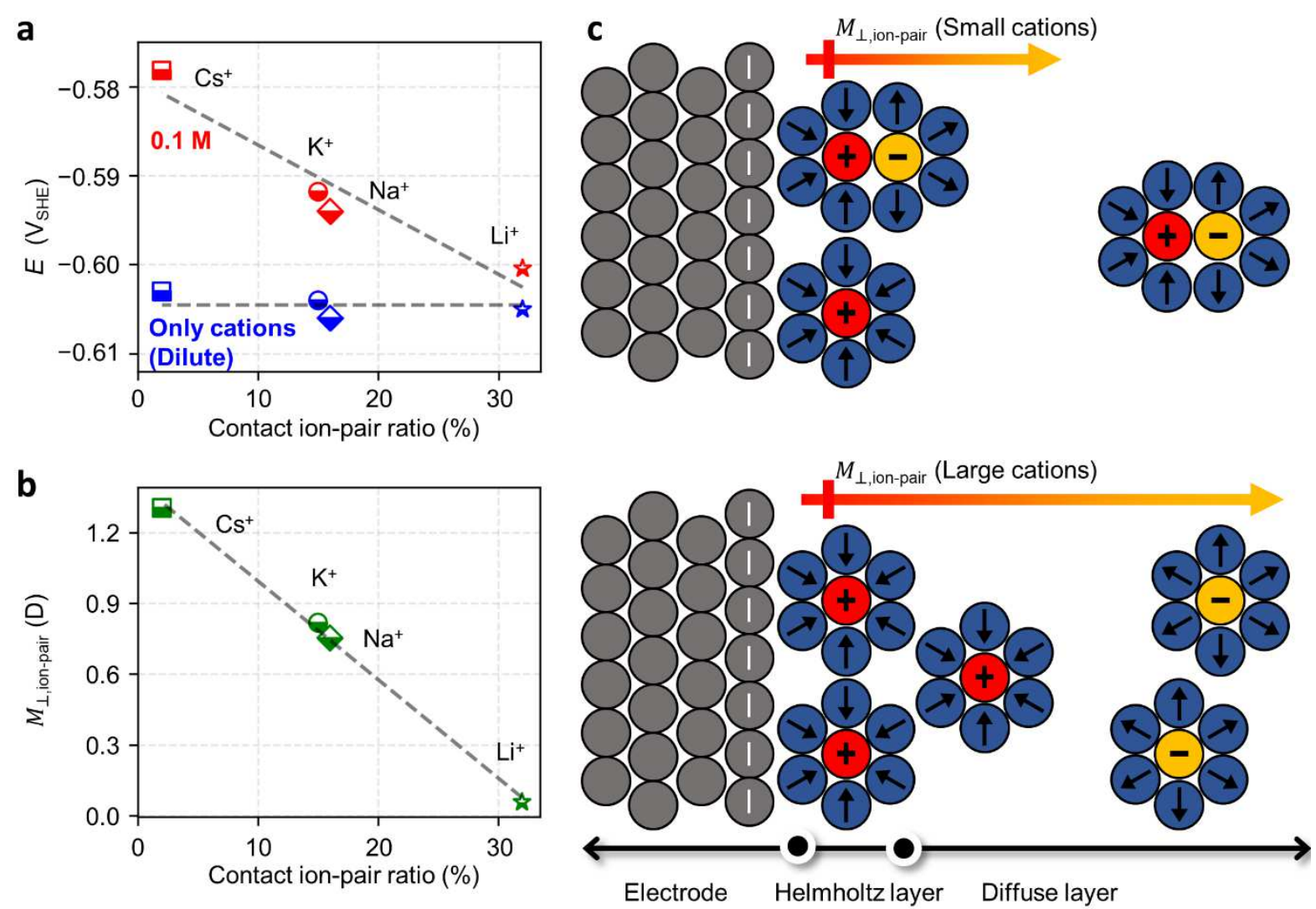

Figure 4. DFT-CES results with the different cation species. a. Electrode potential versus contact ion-pair ratio of each electrolyte. The electrolytes consist of $0.1 \mathrm{M} \mathrm{MHCO}_{3}$ (red; $\mathrm{M}^{+}$is alkali metal cation) and dilute electrolyte (blue), with a surface charge density of $-14 \mu \mathrm{C} \mathrm{cm}^{-2}$. The dilute electrolyte only contains the minimum number of cations sufficient to compensate the charged electrode, whereas $0.1 \mathrm{M}$ electrolytes have additional ion-pairs. The contact ion-pair ratio is calculated from the $0.1 \mathrm{M}$ bulk electrolyte (see details in Figure S15). b. Macroscopic dipole moment of ion-pairs along the $z$-direction, $M_{\perp \text {,ion-pair }}$ of each electrolyte, which is calculated by subtracting the spatial charge density of ions for the dilute case from the $0.1 \mathrm{M}$ case. $\mathbf{c}$. Schematics showing the different screening ability originating from the distinct ion-pairing tendency. The red-yellow graded arrow indicates the $M_{\perp \text {,ion-pair }}$ and the blue circles with the black arrows denote water dipoles. 


\section{Supplementary Files}

This is a list of supplementary files associated with this preprint. Click to download.

- CCETSINatCommsubmisson.docx 